\title{
openheart Myocardial infarction, ST-elevation and non-ST-elevation myocardial infarction and modelled daily pollution concentrations: a case-crossover analysis of MINAP data
}

\author{
Barbara K Butland, ${ }^{1}$ Richard W Atkinson, ${ }^{1}$ Ai Milojevic, ${ }^{2}$ Mathew R Heal, ${ }^{3}$ \\ Ruth M Doherty, ${ }^{4}$ Ben G Armstrong, ${ }^{2}$ Ian A MacKenzie, ${ }^{4}$ Massimo Vieno, ${ }^{5,4}$ \\ Chun Lin, ${ }^{3}$ Paul Wilkinson ${ }^{2}$
}

To cite: Butland BK, Atkinson RW, Milojevic A, et al. Myocardial infarction, ST-elevation and non-STelevation myocardial infarction and modelled daily pollution concentrations: a case-crossover analysis of MINAP data. Open Heart 2016;3:e000429.

doi:10.1136/openhrt-2016000429

- Additional material is available. To view please visit the journal online (http://dx. doi.org/10.1136/openhrt2016-000429).

Received 9 March 2016 Revised 7 June 2016 Accepted 22 June 2016

\section{CrossMark}

${ }^{1}$ Population Health Research Institute and MRC-PHE Centre for Environment and Health, St George's, University of London, London, UK

${ }^{2}$ Department of Social and Environmental Health Research, London School of Hygiene and Tropical Medicine, London, UK

${ }^{3}$ School of Chemistry, University of Edinburgh, Edinburgh, UK

${ }^{4}$ School of GeoSciences, University of Edinburgh, Edinburgh, UK

${ }^{5}$ NERC, Centre for Ecology \& Hydrology, Penicuik, UK

Correspondence to Barbara K Butland; b.butland@sgul.ac.uk

\section{ABSTRACT}

Objectives: To investigate associations between daily concentrations of air pollution and myocardial infarction (MI), ST-elevation MI (STEMI) and non-STelevation MI (NSTEMI).

Methods: Modelled daily ground-level gaseous, total and speciated particulate pollutant concentrations and ground-level daily mean temperature, all at $5 \mathrm{~km} \times 5 \mathrm{~km}$ horizontal resolution, were linked to 202550 STEMI and 322198 NSTEMI events recorded on the England and Wales Myocardial Ischaemia National Audit Project (MINAP) database. The study period was 2003-2010. A case-crossover design was used, stratified by year, month and day of the week. Data were analysed using conditional logistic regression, with pollutants modelled as unconstrained distributed lags $0-2$ days. Results are presented as percentage change in risk per $10 \mu \mathrm{g} / \mathrm{m}^{3}$ increase in the pollutant relevant metric, having adjusted for daily mean temperature, public holidays, weekly influenza consultation rates and a sine-cosine annual cycle.

Results: There was no evidence of an association between $\mathrm{MI}$ or STEMI and any of $\mathrm{O}_{3}, \mathrm{NO}_{2}, \mathrm{PM}_{2.5}, \mathrm{PM}_{10}$ or selected $\mathrm{PM}_{2.5}$ components (sulfate and elemental carbon). For NSTEMI, there was a positive association with daily maximum 1 -hour $\mathrm{NO}_{2}(0.27 \%(95 \% \mathrm{Cl}$ $0.01 \%$ to $0.54 \%)$ ), which persisted following adjustment for $\mathrm{O}_{3}$ and adjustment for $\mathrm{PM}_{2.5}$. The association appeared to be confined to the midland and southern regions of England and Wales.

Conclusions: The study found no evidence of an association between the modelled pollutants (including components) investigated and STEMI but did find some evidence of a positive association between $\mathrm{NO}_{2}$ and NSTEMI. Confirmation of this association in other studies is required.

\section{INTRODUCTION}

Air pollution has been associated with adverse cardiovascular heath events in longterm exposure (cohort) studies and in shortterm (time-series or case-crossover) studies,

\section{KEY QUESTIONS}

What is already known about this subject?

- Evidence from epidemiological studies examining associations between short-term variations in concentrations of ambient air pollution and acute myocardial infarction (MI) is mixed.

- Most studies have focused on urban populations -few have explored the wider geographical coverage (especially for exposure to $\mathrm{PM}_{2.5}$ and its components) offered by the use of atmospheric chemistry transport models (ACTM).

What does this study add?

- Using ACTM data, this study found no evidence of an association between the pollutants investigated $\left(\mathrm{O}_{3}, \mathrm{NO}_{2}, \mathrm{PM}_{2.5}, \mathrm{PM}_{10}\right.$ and the $\mathrm{PM}_{2.5}$ components sulfate and elemental carbon) and MI or ST-elevation MI.

- However, there was evidence of a positive association between $\mathrm{NO}_{2}$ (a traffic related pollutant) and non-ST-elevation $\mathrm{MI}$ which appeared to be independent of $\mathrm{PM}_{2.5}$ and $\mathrm{O}_{3}$.

How might this impact on clinical practice?

- Our findings add to the growing epidemiological literature investigating the acute effects of air pollution on cardiovascular health.

- The identification of susceptible population subgroups most at risk on high pollution days would enable appropriate advice to be formulated and communicated in a timely manner to reduce the risk to health.

and there is mounting evidence from clinical investigations as to potential mechanisms. ${ }^{1-4}$

In terms of the more specific outcome of acute myocardial infarction (MI), epidemiological studies examining the short-term effects of outdoor ambient air pollution have varied in their findings. ${ }^{5-10}$ While a minority of studies suggest an increase in the risk of an MI following exposure to higher 
concentrations of ozone $\left(\mathrm{O}_{3}\right)$, evidence from the literature of an increase in risk following a rise in exposure to the mass of particulates with an aerodynamic diameter $<10 \mu \mathrm{m}\left(\mathrm{PM}_{10}\right)$, or $<2.5 \mu \mathrm{m}\left(\mathrm{PM}_{2.5}\right)$, nitrogen dioxide $\left(\mathrm{NO}_{2}\right)$, carbon monoxide $(\mathrm{CO})$ and sulfur dioxide $\left(\mathrm{SO}_{2}\right)$ is more consistent. ${ }^{5-10}$ Part of the reason for inconsistencies between studies may be due to the different outcome measures used (from emergency department visits and hospital admissions to mortality), the accuracy of diagnosis or different assumptions about the nature of any association (linear or non-linear in the $\log$ relative risk). Results may also be influenced by the relative proportion of MI subtypes in the study population, as well as the source of gasses and the type and source of particle species. The few studies that have presented results for ST-elevation MI (STEMI) and non-STelevation MI (NSTEMI) separately have produced conflicting results. ${ }^{11-13}$ An analysis of data (based on 452343 MI events between 2003 and 2009) from the England and Wales Myocardial Ischaemia National Audit Project (MINAP) ${ }^{14}$ reported small positive associations of $\mathrm{NO}_{2}$ (unconstrained distributed lag model (UDLM) lags 0-4) with all MI and NSTEMI, ${ }^{11}$ while a much smaller study in the USA reported a positive association of $\mathrm{PM}_{2.5}$ (lag 1 hour) with STEMI. ${ }^{12}$

Previous studies have also varied in the accuracy, completeness and representativeness of the pollution data, the choice of pollution metric and exposure period/lag, as well as to the choice and modelling of potential covariates. Most short-term studies to date, including those based on MINAP data, have used pollution monitoring networks to provide their daily exposure assessments. Few have so far explored the potential advantages of using modelled data that have complete coverage over urban and rural areas, diversity (in terms of particle species components) and enable air quality-related policy scenarios to be investigated. The EMEP4UK atmospheric chemistry transport model (ACTM) $)^{15} 16$ is a highresolution regional application of the well-established European Monitoring and Evaluation Programme (EMEP) MSC-W model. ${ }^{17}$ It simulates the evolution of ambient pollution concentrations using official pollutant emission inventories, relevant natural emissions and driving meteorology, through a detailed treatment of atmospheric chemistry and physics. In this paper, we use ACTM data at $5 \mathrm{~km}$ by $5 \mathrm{~km}$ spatial resolution to explore associations between modelled ground-level gaseous, total and speciated particulate pollutant concentrations linked to MI, STEMI and NSTEMI events recorded on the England and Wales MINAP database between 2003 and 2010 .

\section{METHODS}

\section{Outcome data}

The outcome data for the study period of 2003-2010 come from MINAP. This is a register of hospital admissions for acute coronary syndromes (ACS) covering all acute National Health Service hospitals in England and Wales. In addition to discharge diagnosis, the register contains over 100 separate fields of patient-level data, including demographic information (eg, sex, age, smoking status, ethnicity), medical history (eg, history of MI, cerebrovascular disease, peripheral vascular disease, COPD), drug treatment prior to and during the admission and clinical findings (eg, ECG results, symptoms). ${ }^{14}$

For the purpose of this study, we excluded patients with missing geocodes, insufficient information on date of event, missing information on discharge diagnosis or linked to areas outside England and Wales. This left 630116 events occurring during 2003-2010 and recorded on the MINAP database, of which 203804 had a discharge diagnosis of STEMI and 323999 had a discharge diagnosis of NSTEMI (including troponin positive ACS). New left bundle branch block was treated as synonymous with ST-elevation in the diagnosis of STEMI. ${ }^{18}$

\section{Model pollution and weather data}

The pollution data are surface daily outputs (derived from hourly outputs) at $5 \mathrm{~km} \times 5 \mathrm{~km}$ spatial resolution from an ACTM: EMEP4UK version rv4.3. ${ }^{15} 16$ High resolution is achieved through a nested approach whereby a $5 \mathrm{~km} \times 5 \mathrm{~km}$ (inner) domain over the British Isles is nested within, and takes boundary and initial conditions from, a larger $50 \mathrm{~km} \times 50 \mathrm{~km}$ (outer) domain over Europe. The meteorology driving the ACTM comes from the Weather Research and Forecasting (WRF) model version 3.1.1 ${ }^{19}$ which is constrained to contemporary meteorological observations, ensuring that the applied meteorology is representative of the real weather conditions prevailing throughout the simulated period. Pollutant and pollutant-precursor emissions over the UK were taken from the UK National Atmospheric Emissions Inventory ${ }^{20}$ and for the outer domain from EMEP estimates provided by the Centre for Emission Inventories and Projections. ${ }^{21}$

The pollutant metrics investigated in this study were daily means of $\mathrm{PM}_{2.5}, \mathrm{PM}_{10}$, sulfate $\left(\mathrm{SO}_{4}^{2-}\right)$ and elemental carbon (EC) and daily maximum 8-hour-running mean for $\mathrm{O}_{3}$ and daily maximum 1-hour mean for $\mathrm{NO}_{2}$. The weather metric was daily mean temperature (see below).

\section{Monitor pollution data}

Monitor data were used only in the assessment of model performance (see below and online supplementary table S1). For this purpose, daily maximum 8-hour running mean $\mathrm{O}_{3}$, daily maximum 1-hour $\mathrm{NO}_{2}$, daily mean $\mathrm{PM}_{2.5}$ and daily mean $\mathrm{PM}_{10}$ were calculated for 2001-2010 using a 75\% data capture threshold on hourly data from urban background and rural monitoring sites of the Automatic Urban and Rural Network (AURN) of the UK Department for Environment, Food and Rural Affairs. ${ }^{22} \mathrm{PM}_{2.5}$ data were not available for the full period of interest, as the monitoring of this pollutant began only in the latter part of the decade. 
Between 2001 and 2010 there were changes in the instrumentation used to monitor $\mathrm{PM}_{10}$.

\section{Validation of the pollution and weather models}

The EMEP4UK model has undergone extensive validation, ${ }^{15} 16 \quad 23$ and their potential for use in epidemiological analyses is beginning to be explored. ${ }^{24}$ For 2001-2010 the average Pearson correlation over time $(\bar{r})$ between urban background monitored pollution concentrations at AURN monitoring sites, ${ }^{22}$ and their equivalents for the EMEP4UK model grid incorporating the monitor, was relatively high for daily maximum 8-hour $\mathrm{O}_{3}$ (no. of sites $(\mathrm{n})=63 ; \bar{r}=0.76$; $\mathrm{SD}(\mathrm{r})=0.04$ ) and daily mean $\mathrm{PM}_{2.5}(\mathrm{n}=39 ; \bar{r}=0.69$; $\mathrm{SD}(\mathrm{r})=0.09)$ and lower for daily mean $\mathrm{PM}_{10}(\mathrm{n}=57 ; \bar{r}=0.50 ; \mathrm{SD}(\mathrm{r})=0.07)$ and maximum 1-hour $\mathrm{NO}_{2}(\mathrm{n}=75 ; \bar{r}=0.54$; $\mathrm{SD}(\mathrm{r})=0.10)$.

Imprecision in the estimation of daily pollution concentrations whether modelled or measured may on average lead to some attenuation (ie, bias towards the null) in estimates of the log relative risk obtained from epidemiological analyses. Simple predictions as to the level of attenuation (ie, percentage bias towards the null) that might be expected due to the use of ACTM data are explored in online supplementary table S1.

Since monitored temperature data are available for only a small subset of the model grid boxes, we used the WRF model 2-metre temperature for covariate adjustment. As discussed above, the WRF model was nudged with reanalysis data every 6 hours to closely represent observations such as the surface temperature.

For daily mean temperature, the average modelmonitor correlation over time was very high $(\mathrm{n}=93$; $\bar{r}=0.98 ; \mathrm{SD} \quad(\mathrm{r})=0.01)$ and plots of the relationship between MI and modelled temperature (see online supplementary figure S1) are similar to those previously published by Bhaskaran et $a l^{25}$ using the MINAP database and monitored temperature.

\section{Data linkage}

Each MI event was linked to the modelled weather and pollutant exposure data in the $5 \mathrm{~km}$ grid closest to the output area (OA) of the patient's residence (using OA centroids rounded to $1000 \mathrm{~m}$ to avoid personal identification).

\section{Statistical methods}

The analysis was conducted at the level of the individual using a time-stratified case-crossover analysis. ${ }^{26}$ For each case we defined the index day as the day of the MI and the referent or control days as those days within the same month and on the same day of the week as the event day. ${ }^{26}$ Within each individual we then compared the modelled pollutant exposures between the index and referent days as in a 1:M matched case-control study. The analysis was conducted in STATA V.12 (StataCorp: Stata Statistical Software: Release 12. College Station, TX: StataCorp LP; 2011) using conditional logistic regression. In this way each subject acted as their own control, automatically adjusting for potential non-time varying/time-insensitive confounders such as sex, age, smoking status, socioeconomic status etc. The matched sets or strata were defined in time (ie, year, month, day of the week) to remove trend and seasonal pattern and additional covariates were added to the regression models to adjust for temperature, public holidays, influenza epidemics and residual seasonality. The primary regression model included: two natural cubic splines (each with 5 degrees of freedom (df)) representing mean daily temperature averaged across the day and the day before (mean lag $0-1)$ and mean daily temperature averaged across days 2-6 before (mean lag 2-6); a binary indicator variable for public holidays; the Royal College of General Practitioners (RCGP) England and Wales weekly consultation rate for influenza-like illness for the week of the event; ${ }^{27}$ and sine and cosine terms representing a simple annual cycle. A priori, pollutants were included in analyses as unconstrained distributed lags 0-2 days (UDLM $0-2)$. Under the rare disease assumption, ORs from conditional logistic regression were interpreted as relative risks and are presented as such in tables and plots with their $95 \%$ CIs.

Possible effect modification by season (autumn= September-November, winter=December-February, spring= March-May; and summer=June-August) and, where applicable, by sex and age group $(\leq 64,65-74,75-84$, $\geq 85$ ) was investigated by including appropriate interaction terms in the regression models and testing for an improvement in fit using likelihood ratio tests. However, when investigating effect modification by Government Office Region (10 in England and Wales), a two-stage analysis was employed whereby ORs from region-specific conditional logistic regressions were meta-analysed using METAN in STATA V.12, (StataCorp LP; 2011) to obtain overall relative risks (across all regions), subtotal relative risks for each of three broader areas or 'super regions' (ie, the North, Midlands and the South) and tests of heterogeneity between regions and between 'super regions'. This approach facilitated region-specific covariate adjustment.

Underlying our analyses is the assumption that any association between MI and pollution is approximately log-linear. This assumption was investigated in sensitivity analysis by fitting natural cubic splines (each with $2 \mathrm{df}$ ) to simple pollutant averages (averaged over lags $0-2$ ) and testing for non-linearity using the Wald $\chi^{2}$ tests $(\mathrm{df}=1)$.

\section{RESULTS}

Having excluded records with missing data on exposures or covariates, our main analysis was based on 626239 events occurring during the study period (ie, 20032010) and recorded on the MINAP database. The number of control days ranged from 1 to 4 per case but with $<1 \%$ of cases matched to only 1 or 2 controls. Of these 626239 events, 202550 were diagnosed on 
discharge as STEMI, 322198 as NSTEMI and 37579 as ACS (troponin negative). The remaining 63912 had discharge diagnoses, including threatened MI, chest pain of uncertain cause, unconfirmed MI, Takotsubo cardiomyopathy, ACS (troponin unspecified), PCI-related MI and other (ie, admitted with clinical suspicion of cardiac pain but diagnosis other than cardiac ischaemia confirmed). Our definition of ALL MI includes all 626239 events and is therefore broad and inclusive. The median (IQR) age, in years, of cases was 70.6 (59.1-80.0) for ALL MI, 66.2 (56.0-76.5) for STEMI and 74.2 (63.282.4) for NSTEMI and the percentage $(\mathrm{n} / \mathrm{N})$ male was $65 \% \quad(404374 / 624926), 70 \% \quad(141971 / 202$ 024) and $62 \%$ (199 216/321 633), respectively.

\section{Association with pollution}

In our primary logistic regression models adjusted for temperature lags $0-1$ and 2-6 days, influenza, public holidays and residual seasonality (table 1), there was no evidence of an association of ALL MI or STEMI with any of $\mathrm{O}_{3}, \mathrm{NO}_{2}, \mathrm{PM}_{10}$ or $\mathrm{PM}_{2.5}$. For NSTEMI, there was a statistically significant $(\mathrm{p}=0.043)$ positive association with $\mathrm{NO}_{2}$ suggestive of a $0.27 \% \quad(95 \%$ CI $0.01 \%$ to $0.54 \%$ ) increase in risk per $10 \mu \mathrm{g} / \mathrm{m}^{3}$ increase in the daily 1-hour maximum concentration. This association did not differ significantly by season $(\mathrm{p}=0.571)$, age-group $(\mathrm{p}=0.986)$ or sex $(\mathrm{p}=0.859)$. It also persisted following adjustment for $\mathrm{O}_{3}$, and increased in magnitude following adjustment for $\mathrm{PM}_{2.5}(\mathrm{p}=0.008)$ (table 1 : two pollutant models).

\section{Effect modification by season}

Returning to single pollutant models, evidence of modification by season (table 2) was observed for $\mathrm{PM}_{2.5}$ in relation to ALL MI and for $\mathrm{O}_{3}$ in relation to STEMI. For $\mathrm{O}_{3}$ there was evidence of a negative association with STEMI in the autumn and for $\mathrm{PM}_{2.5}$ there was evidence of a positive association with ALL MI in the autumn. However, in both cases, there was no consistency in the direction of relative risk estimates across the four seasons.

\section{Effect modification by region}

We next investigated differences in association between Government Office Regions, having adjusted for covariates at the regional level (table 3). With respect to $\mathrm{NO}_{2}$, $\mathrm{PM}_{10}$ and $\mathrm{PM}_{2.5}$, regression models included additional regional-level adjustment for ozone (lags 0,1 and 2).

For ALL MI and for STEMI there was no evidence of heterogeneity in association between regions or between 'super regions' (North, Midlands, South) whether in relation to $\mathrm{O}_{3}, \mathrm{NO}_{2}, \mathrm{PM}_{2.5}$ or $\mathrm{PM}_{10}$. In contrast for $\mathrm{NO}_{2}$ and NSTEMI, subtotal relative risks for the Midlands and the South were significant and $>1$, suggestive of increases of $0.79 \%(0.13 \%$ to $1.45 \%)$ and $0.51 \%(0.09 \%$ to $0.94 \%$ ) per $10 \mu \mathrm{g} / \mathrm{m}^{3}$, respectively, whereas in the North the subtotal relative risk was $<1$ and nonsignificant (test for heterogeneity between 'super regions', $\mathrm{p}=0.022$ ). For $\mathrm{O}_{3}$ and NSTEMI, associations differed significantly between regions $(p=0.006)$ but not between 'super regions'.

When we compared the overall estimates (ie, over all regions) in table 3 with their corresponding values in table 1, it appeared that adjustment for region had little effect.

\section{$\mathbf{P M}_{2.5}$ components}

Table 4 displays the results from investigating the associations between our three outcomes and two selected $\mathrm{PM}_{2.5}$ components. The two components tabulated are EC (emitted from combustion) and sulfate $\left(\mathrm{SO}_{4}^{2-}\right.$, formed

\begin{tabular}{|c|c|c|c|}
\hline Pollutant† & $\begin{array}{l}\text { All MI } \\
\text { Percentage change } \\
(95 \% \mathrm{Cl})\end{array}$ & $\begin{array}{l}\text { STEMI } \\
\text { Percentage change } \\
(95 \% \mathrm{Cl})\end{array}$ & $\begin{array}{l}\text { NSTEMI } \\
\text { Percentage change } \\
(95 \% \mathrm{Cl})\end{array}$ \\
\hline \multicolumn{4}{|c|}{ Single pollutant regression model } \\
\hline $\mathrm{O}_{3}$ & $-0.06(-0.29$ to 0.17$)$ & $-0.16(-0.57$ to 0.25$)$ & $-0.05(-0.37$ to 0.28$)$ \\
\hline $\mathrm{NO}_{2}$ & $0.09(-0.10$ to 0.28$)$ & $-0.16(-0.49$ to 0.18$)$ & 0.27 (0.01 to 0.54$)$ \\
\hline $\mathrm{PM}_{2.5}$ & $-0.04(-0.45$ to 0.38$)$ & $-0.34(-1.06$ to 0.39$)$ & $-0.15(-0.72$ to 0.43$)$ \\
\hline $\mathrm{PM}_{10}$ & $-0.20(-0.53$ to 0.13$)$ & $-0.37(-0.95$ to 0.21$)$ & $-0.34(-0.80$ to 0.12$)$ \\
\hline \multicolumn{4}{|c|}{ Two pollutant regression model } \\
\hline $\mathrm{NO}_{2}$ (adjusted for $\mathrm{O}_{3}$ ) & $0.07(-0.13$ to 0.27$)$ & $-0.23(-0.57$ to 0.12$)$ & $0.28(0.00$ to 0.57$)$ \\
\hline $\mathrm{NO}_{2}$ (adjusted for $\mathrm{PM}_{2.5}$ ) & $0.14(-0.08$ to 0.37$)$ & $-0.07(-0.46$ to 0.32$)$ & $0.43(0.11$ to 0.74$)$ \\
\hline $\mathrm{PM}_{2.5}$ (adjusted for $\mathrm{O}_{3}$ ) & $-0.04(-0.46$ to 0.37$)$ & $-0.36(-1.09$ to 0.37$)$ & $-0.15(-0.73$ to 0.43$)$ \\
\hline $\mathrm{PM}_{2.5}$ (adjusted for $\mathrm{NO}_{2}$ ) & $-0.17(-0.65$ to 0.32$)$ & $-0.20(-1.06$ to 0.66$)$ & $-0.59(-1.26$ to 0.10$)$ \\
\hline $\mathrm{PM}_{10}$ (adjusted for $\mathrm{O}_{3}$ ) & $-0.20(-0.53$ to 0.13$)$ & $-0.38(-0.96$ to 0.21$)$ & $-0.34(-0.80$ to 0.12$)$ \\
\hline
\end{tabular}


Table 2 Estimates for the season-specific percentage change in risk (95\% Cl) per $10 \mu \mathrm{g} / \mathrm{m}^{3}$ increase in pollutant and tests for modification by season*: Single pollutant modelst

\begin{tabular}{|c|c|c|c|c|c|c|}
\hline \multirow[b]{2}{*}{ Pollutant } & \multicolumn{2}{|l|}{ All MI } & \multicolumn{2}{|l|}{ STEMI } & \multicolumn{2}{|l|}{ NSTEMI } \\
\hline & $\begin{array}{l}\text { Percentage change } \\
(95 \% \mathrm{Cl})\end{array}$ & p Value* & $\begin{array}{l}\text { Percentage change } \\
(95 \% \mathrm{Cl})\end{array}$ & p Value* & $\begin{array}{l}\text { Percentage change } \\
(95 \% \mathrm{Cl})\end{array}$ & p Value* \\
\hline \multicolumn{7}{|l|}{$\mathrm{O}_{3}$} \\
\hline Autumn & $-0.38(-0.85$ to 0.10$)$ & 0.446 & $-1.15(-1.98$ to -0.31$)$ & 0.040 & $-0.10(-0.76$ to 0.57$)$ & 0.785 \\
\hline Winter & $0.00(-0.37$ to 0.38$)$ & & $0.18(-0.48$ to 0.85$)$ & & $0.04(-0.49$ to 0.56$)$ & \\
\hline Spring & $0.19(-0.29$ to 0.67$)$ & & $0.39(-0.46$ to 1.24$)$ & & $-0.03(-0.71$ to 0.65$)$ & \\
\hline Summer & $-0.07(-0.52$ to 0.38$)$ & & $-0.24(-1.04$ to 0.56$)$ & & $-0.14(-0.77$ to 0.50$)$ & \\
\hline \multicolumn{7}{|l|}{$\mathrm{NO}_{2}$} \\
\hline Autumn & $0.11(-0.26$ to 0.47$)$ & 0.419 & $-0.07(-0.71$ to 0.58$)$ & 0.060 & $0.13(-0.38$ to 0.64$)$ & 0.571 \\
\hline Winter & $0.16(-0.18$ to 0.51$)$ & & $0.26(-0.34$ to 0.86$)$ & & $0.12(-0.36$ to 0.60$)$ & \\
\hline Spring & $-0.05(-0.39$ to 0.28$)$ & & $-0.55(-1.13$ to 0.03$)$ & & $0.38(-0.09$ to 0.86$)$ & \\
\hline Summer & $0.23(-0.27$ to 0.73$)$ & & $-0.21(-1.09$ to 0.68$)$ & & $0.64(-0.07$ to 1.36$)$ & \\
\hline \multicolumn{7}{|l|}{$\mathrm{PM}_{2.5}$} \\
\hline Autumn & $0.98(0.20$ to 1.76$)$ & 0.030 & $0.76(-0.62$ to 2.16$)$ & 0.639 & $1.13(0.05$ to 2.23$)$ & 0.119 \\
\hline Winter & $-0.70(-1.52$ to 0.13$)$ & & $-0.92(-2.35$ to 0.54$)$ & & $-1.13(-2.27$ to 0.02$)$ & \\
\hline Spring & $-0.39(-1.09$ to 0.31$)$ & & $-0.41(-1.64$ to 0.84$)$ & & $-0.46(-1.45$ to 0.54$)$ & \\
\hline Summer & $0.01(-1.12$ to 1.15$)$ & & $-1.28(-3.26$ to 0.75$)$ & & $-0.19(-1.78$ to 1.42$)$ & \\
\hline \multicolumn{7}{|l|}{$\mathrm{PM}_{10}$} \\
\hline Autumn & $0.51(-0.14$ to 1.16$)$ & 0.155 & $0.53(-0.62$ to 1.70$)$ & 0.280 & $0.47(-0.44$ to 1.39$)$ & 0.510 \\
\hline Winter & $-0.43(-0.99$ to 0.15$)$ & & $-0.75(-1.75$ to 0.26$)$ & & $-0.64(-1.43$ to 0.15$)$ & \\
\hline Spring & $-0.61(-1.20$ to -0.01$)$ & & $-0.26(-1.30$ to 0.80$)$ & & $-0.79(-1.62$ to 0.04$)$ & \\
\hline Summer & $-0.13(-0.87$ to 0.61$)$ & & $-1.06(-2.37$ to 0.26$)$ & & $-0.20(-1.24$ to 0.86$)$ & \\
\hline $\begin{array}{l}\text { *The } p \text { value } \\
\text { (December- } \\
\text { †The conditi } \\
\text { influenza-like } \\
0-1 \text { and mea } \\
\text { †Pollutant m } \\
\text { Ml, myocard }\end{array}$ & $\begin{array}{l}\text { the table relate to likelihoo } \\
\text { ruary); spring (March-May) } \\
\text { I logistic regression model f } \\
\text { less consultation rates per } \\
\text { ag } 2-6 \text { ), public holidays and } \\
\end{array}$ & $\begin{array}{l}\text { atio tests } f \\
\text { nd summe } \\
\text { the polluta } \\
000 \text { Engl } \\
\text { sine/cosir } \\
\text { an } \mathrm{PM}_{10} \text {, }\end{array}$ & $\begin{array}{l}\text { season interaction. Seasc } \\
\text { une-August). } \\
\text { as unconstrained distribute } \\
\text { and Wales population, tw } \\
\text { nnual cycle. } \\
\text { y maximum 1-hour } \mathrm{NO}_{2} \text {, d } \\
\text { EMI, ST-elevation } \mathrm{MI}^{\text {. }}\end{array}$ & $\begin{array}{l}\text { defined as } \\
\text { gs } 0-2 \text { an } \\
\text { atural cubi } \\
\text { maximum }\end{array}$ & $\begin{array}{l}\text { lutumn (September-Novem } \\
\text { pliusts for, the weekly RCG } \\
\text { plines }(\mathrm{df}=5 \text { ) for temperatur } \\
\text { hour mean } \mathrm{O}_{3} \text {. }\end{array}$ & (mean lag \\
\hline
\end{tabular}

within the atmosphere from $\mathrm{SO}_{2}$ ). The conditional logistic regression models adjust for temperature at lags 0-1 and 2-6 days, public holidays, influenza and residual seasonality. Neither EC nor $\mathrm{SO}_{4}^{2-}$ was associated with ALL MI, STEMI or NSTEMI either before or after additional adjustment for $\mathrm{O}_{3}$ at lags 0,1 and 2 .

\section{Sensitivity analysis}

As part of our sensitivity analyses, we returned to our single pollutant regressions (table 1) and plotted the individual components of each UDLM as the percentage change in risk per $10 \mu \mathrm{g} / \mathrm{m}^{3}$. From figure 1 , it appeared that the association between $\mathrm{NO}_{2}$ and NSTEMI was primarily due to concentrations on the day (lag 0 ) rather than on the 1 day (lag 1) or 2 days prior (lag 2).

Next we looked for evidence of non-linearity in the associations between simple pollution averages (across lags 0,1 and 2) and the log relative risks of ALL MI, STEMI and NSTEMI. Having adjusted for covariates, we found no evidence of non-linearity based on Wald tests with $1 \mathrm{df}$ (all $\mathrm{p}>0.19$ ).

Finally, to investigate the sensitivity of our findings to the level of control for seasonality, we re-ran our single pollutant regression models without the sine and cosine terms and observed little change in risk estimates and CIs (see online supplementary table S2).

\section{DISCUSSION}

\section{Main findings}

We investigated associations between gaseous and particulate air pollution and three outcomes, and found no evidence of associations except for one positive association between modelled $\mathrm{NO}_{2}$ and NSTEMI, suggestive of a $0.27 \%$ increase in NSTEMI per $10 \mu \mathrm{g} / \mathrm{m}^{3}$ increase in daily maximum 1-hour $\mathrm{NO}_{2}$ (UDLM $0-2$ ). This association increased in magnitude and statistical significance following adjustment for $\mathrm{PM}_{2.5}$. While not significant in any one season, the relative risk for $\mathrm{NO}_{2}$ and NSTEMI in our single pollutant model was consistently $>1$ in the autumn, winter, spring and summer months (table 2). However, this consistency was not replicated in our regional analysis, which suggested that any positive association between $\mathrm{NO}_{2}$ and NSTEMI was confined to the Midlands and the South (table 3). The lack of association with $\mathrm{EC}$ and $\mathrm{SO}_{4}^{2-}$ is noteworthy given their novelty and what they represent.

\section{Comparison with other studies}

A recent systematic review of air pollution and $\mathrm{MI}^{10}$ identified 34 time-series/case-crossover studies published between 1997 and 2011 for inclusion in meta-analyses. The studies were mainly from the USA and Europe (including two from the UK) and varied in their source 
Table 3 A meta-analysis, combining Government Office Region-specific relative risk estimates by 'super region' (North, Midlands, South) $\dagger$

\section{Estimated percentage change in risk $(95 \% \mathrm{Cl})$ per $10 \mu \mathrm{g} / \mathrm{m}^{3}$ increase in pollutantł}

\begin{tabular}{|c|c|c|}
\hline Disease & $\begin{array}{l}\text { Pollutant¥ } \\
\text { (UDLM 0-2) }\end{array}$ & North \\
\hline \multirow[t]{4}{*}{ All MI } & $\mathrm{O}_{3}$ & $0.05(-0.33$ to 0.44$)$ \\
\hline & $\mathrm{NO}_{2}$ & $-0.17(-0.50$ to 0.16$)$ \\
\hline & $\mathrm{PM}_{2.5}$ & -0.51 ( -1.24 to 0.22$)$ \\
\hline & $\mathrm{PM}_{10}$ & $-0.47(-1.05$ to 0.12$)$ \\
\hline \multirow[t]{4}{*}{ STEMI } & $\mathrm{O}_{3}$ & $-0.16(-0.85$ to 0.54$)$ \\
\hline & $\mathrm{NO}_{2}$ & $-0.21(-0.81$ to 0.39$)$ \\
\hline & $\mathrm{PM}_{2.5}$ & $-1.08(-2.39$ to 0.24$)$ \\
\hline & $\mathrm{PM}_{10}$ & $-1.05(-2.10$ to 0.01$)$ \\
\hline \multirow[t]{4}{*}{ NSTEMI } & $\mathrm{O}_{3}$ & $0.27(-0.26$ to 0.80$)$ \\
\hline & $\mathrm{NO}_{2}$ & $-0.20(-0.67$ to 0.26$)$ \\
\hline & $\mathrm{PM}_{2.5}$ & $-0.36(-1.38$ to 0.66$)$ \\
\hline & $\mathrm{PM}_{10}$ & $-0.22(-1.03$ to 0.60$)$ \\
\hline
\end{tabular}

Midlands

$-0.29(-0.79$ to 0.21$)$

$0.25(-0.21$ to 0.71$)$

$0.47(-0.42$ to 1.36$)$

$0.14(-0.56$ to 0.85$)$

$-0.36(-1.17$ to 0.47$)$

$-0.07(-0.82$ to 0.68$)$

$-0.07(-1.53$ to 1.41$)$

$-0.19(-1.34$ to 0.97$)$

$-0.22(-0.92$ to 0.49$)$

$0.79(0.13$ to 1.45$)$

0.68 ( -0.58 to 1.95$)$

$0.38(-0.62$ to 1.39$)$
South

$0.04(-0.40$ to 0.32$)$

$0.21(-0.09$ to 0.51$)$

$0.01(-0.61$ to 0.63$)$

-0.18 ( -0.67 to 0.31$)$

-0.35 ( -0.88 to 0.19$)$

$-0.17(-1.27$ to 0.95$)$

0.01 ( -0.88 to 0.89$)$

$-0.27(-0.78$ to 0.23$)$

0.51 (0.09 to 0.94$)$

$-0.42(-1.29$ to 0.45$)$

$-0.79(-1.48$ to -0.11$)$
-0.02 ( -0.66 to 0.62$)$
Test of heterogeneity

between

'Super regions' Regions

p Value

p Value

$-0.06(-0.29$ to 0.17$)$

$0.08(-0.12$ to 0.28$)$

$-0.06(-0.48$ to 0.36$)$

-0.20 ( -0.53 to 0.13$)$

$-0.15(-0.56$ to 0.26$)$

-0.24 ( -0.59 to 0.11$)$

$-0.42(-1.16$ to 0.31$)$

$-0.36(-0.95$ to 0.22$)$

-0.06 ( -0.38 to 0.26$)$

0.30 (0.01 to 0.58 )

$-0.16(-0.75$ to 0.42$)$

0.552

0.185

0.236

0.424

0.822

0.838

0.500

0.308

0.307

0.022

-0.36 ( -0.82 to 0.11$)$

0.155

\subsection{1}

0.596

0.429

0.747

0.961

0.994

0.629

0.102

0.006

0.353

0.826

0.786

${ }^{*}$ Adjusted for a sine/cosine annual cycle, the weekly RCGP influenza-like illness consultation rates per 100000 England and Wales population, region-specific natural cubic splines for

temperature (mean lag $0-1$ and mean lag 2-6) and public holidays. Relative risk estimates for $\mathrm{NO}_{2}, \mathrm{PM}_{2.5}$ and $\mathrm{PM}_{10}$ additionally adjusted for $\mathrm{O}_{3}$ (UDLM 0-2).

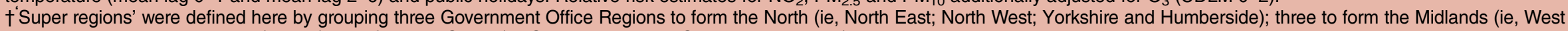
Midlands; East Midlands; Wales); and four to form the South (ie, South West; East; South East; London).

fPollutant metrics: daily mean $\mathrm{PM}_{25}$, daily mean $\mathrm{PM}_{10}$, daily maximum 1-hour $\mathrm{NO}_{2}$, daily maximum 8-hour mean $\mathrm{O}_{3}$.

MI, myocardial infarction; NSTEMI, non-ST-elevation MI; STEMI, ST-elevation MI; UDLM, unconstrained distributed lag model. 
Table 4 Estimates for the percentage change in risk $(95 \% \mathrm{Cl})$ per one IQR ${ }^{*}$ increase in pollutant: single and two pollutant modelst

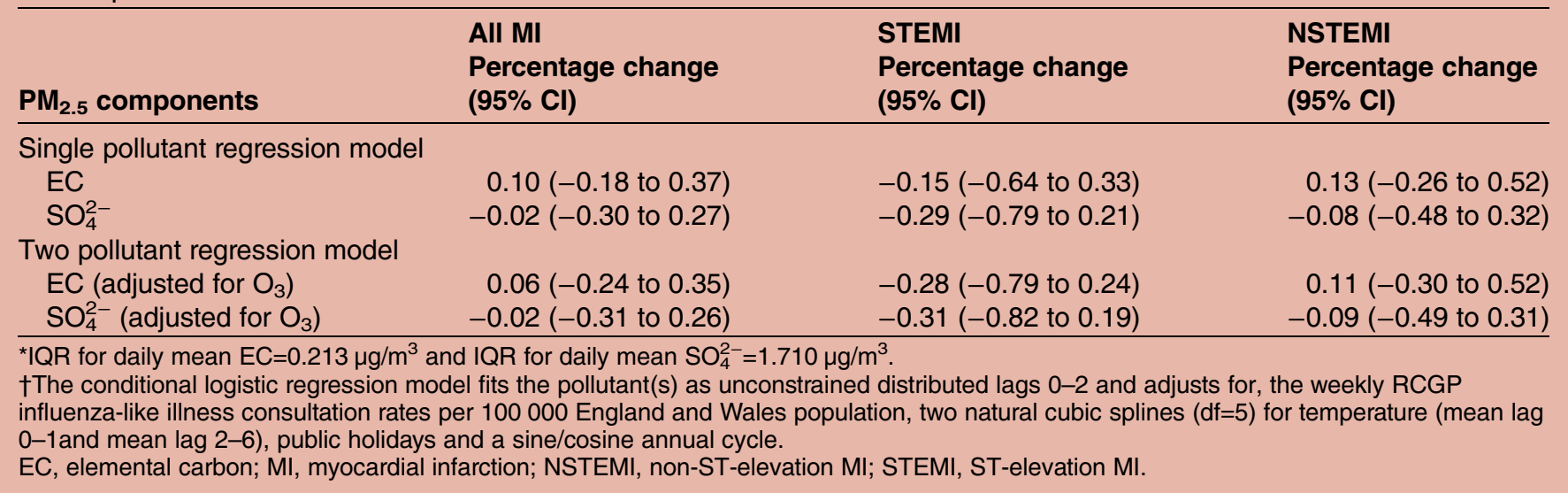

of outcome data (eg, hospital admissions, death registries, MI registries). In common with our results, the review found no evidence of an association between MI and $\mathrm{O}_{3}$ (lag 0 ). However, it reported statistically significant increases in the risk of MI of $1.1 \%, 0.6 \%$ and $2.5 \%$ per $10 \mu \mathrm{g} / \mathrm{m}^{3}$ increases in $\mathrm{NO}_{2}$ (lag 1), $\mathrm{PM}_{10}$ (lag 0) and $\mathrm{PM}_{2.5}$ (lag 1), respectively. These represent very different relative risks to those observed (UDLM 0-2) in our study $(0.09 \%,-0.20 \%,-0.04 \%$, respectively). In particular, the increase in risk for $\mathrm{PM}_{2.5}$ is not apparent in our study. One possible explanation for the difference between our finding and those from the review (besides obvious differences of time-period, geography and outcome measure) is our use of modelled rather than monitored pollutant data. We, therefore, compared our findings with those of a previously published analysis of the MINAP database (2003-2009) by Milojevic et $a l^{11}$ which investigated associations between MI and nearest monitor pollution concentrations (up to $50 \mathrm{~km}$ distant from residential address). In common with our own results, they found no evidence of positive associations with $\mathrm{O}_{3}, \mathrm{PM}_{2.5}$ or $\mathrm{PM}_{10}$ but a significant positive association of daily mean $\mathrm{NO}_{2}$ (lags 0-4) with NSTEMI, although their estimated increase in risk was more marked $\left(0.68 \%\right.$ per $10 \mu \mathrm{g} / \mathrm{m}^{3}$ increase in $\mathrm{NO}_{2}(95 \%$ CI $0.07 \%$ to $\left.1.3 \%)\right)$. One possible explanation for this difference is the different uncertainties in the monitor-based pollution data used by Milojevic et al (measurements made up to $50 \mathrm{~km}$ from residential address) and the model-based exposure assessment used here (see online supplementary table S1).

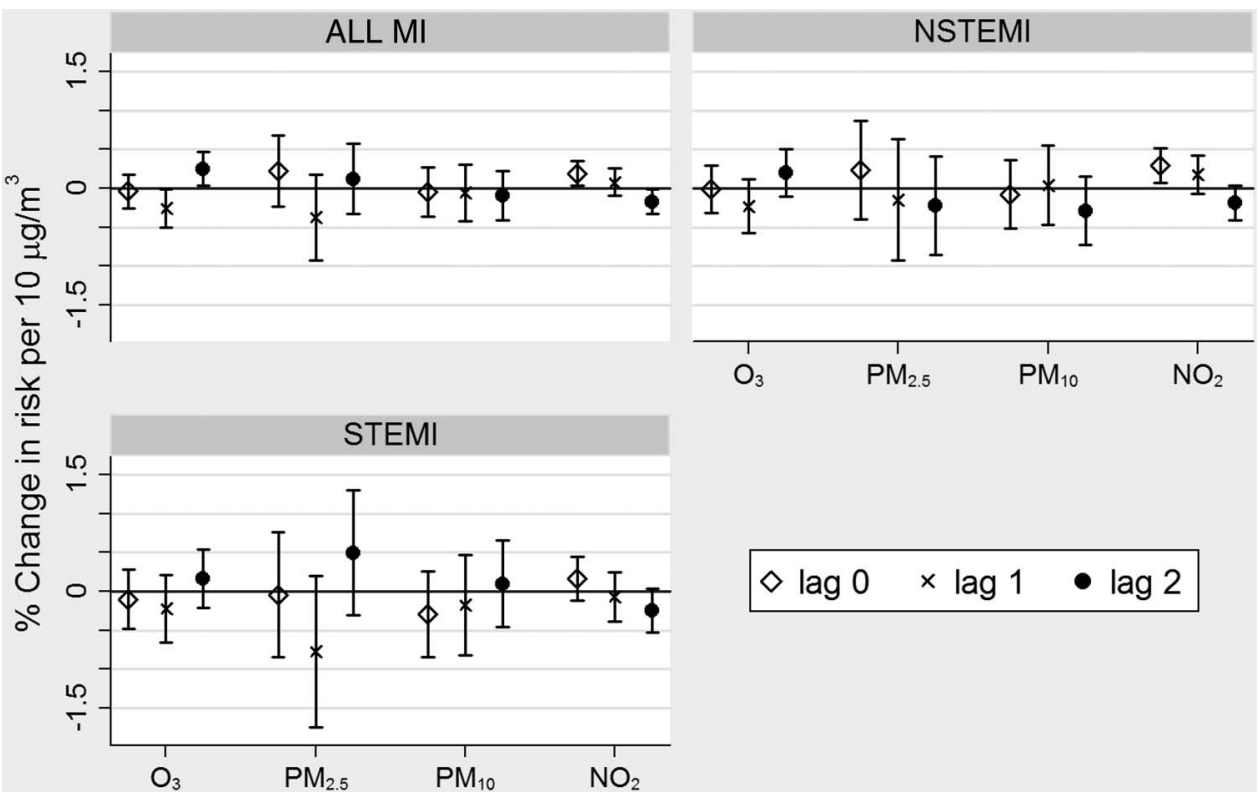

Figure 1 Associations between atmospheric chemistry transport model pollution concentrations at lags 0,1 and 2 and myocardial infarction (\% change in risk per $10 \mu \mathrm{g} / \mathrm{m}^{3}$ increase in pollutant). Pollutant metrics: daily mean $\mathrm{PM}_{2.5}$, daily mean $\mathrm{PM}_{10}$, daily maximum 1-hour $\mathrm{NO}_{2}$, daily maximum 8-hour mean $\mathrm{O}_{3}$. 


\section{Strengths and limitations}

One of the strengths of using MINAP data is that it provides us with a large number of events and hence good statistical power for detecting associations with ALL MI but also with the MI subtypes of STEMI and NSTEMI. However, given the consideration of three outcomes and six pollutants in our analyses, the possibility of obtaining a spurious significant association cannot be discounted.

We acknowledge the potential for modelled pollution concentrations based on any ACTM to introduce more classical measurement error into a time series analysis than monitor data and hence lead to greater attenuation in relative risk estimates. However, based on our comparison of model and monitor data in online supplementary table S1 and our previous statistical simulation study ${ }^{24}$ we expect this to be less of an issue for $\mathrm{O}_{3}$ and for urban $\mathrm{PM}_{2.5}$. Measurement error (classical and Berkson) may also lead to a reduction in statistical power, although, for ACTMs, the ability to provide more complete pollutant time series may partly compensate by limiting any reduction in sample size due to missing data.

One advantage of using modelled pollution data is that we can obtain geographically complete data, as measurements of $\mathrm{PM}_{2.5}$ and other species are limited (in space and time) over the UK. In addition, models can provide particulate matter component data, which, in England and Wales, are sparsely monitored, or restricted to intensive field campaigns, and hence for which little historical data are available. While, in this study, we found no evidence of associations with the EC or sulfate components of $\mathrm{PM}_{2.5}$, there may be associations with other particle component matter not yet investigated.

\section{Critical exposure period}

If there is a detrimental effect of some pollutants, it is not clear whether these effects are immediate (in the few hours prior to the event), delayed or cumulative. A small study of $\mathrm{MI}$ and particulate air pollution in New York reported a positive association of STEMI with $\mathrm{PM}_{2.5}$ exposure in the 1 hour prior to event, with ORs for the 3, 12 and 24 hours prior to event, $>1$ but nonsignificant. ${ }^{12}$ Similarly, a large, though exploratory, study of air pollution and acute MI in Alberta, Canada, reported positive associations of NSTEMI in the 65 and over age group with average $\mathrm{NO}_{2}$ exposures in the 6, 12 and 24 hours prior to event (suggesting elevations in risk of $3.7 \%, 3.8 \%$ and $3.7 \%$ per $10 \mu \mathrm{g} / \mathrm{m}^{3}$, respectively). ${ }^{13}$

In terms of MINAP, a previous study of the database (2003-2006) by Bhaskaran et $a l,{ }^{28}$ found evidence of positive associations between $\mathrm{MI}$ and $\mathrm{NO}_{2}$ and $\mathrm{PM}_{10}$ exposure in the 1-6 hours prior to event (suggesting elevations in risk of $1.1 \%$ and $1.2 \%$ per $10 \mu \mathrm{g} / \mathrm{m}^{3}$, respectively) but no evidence of associations with exposures in the 7-12, 13-18, 19-24 or 25-72 hours prior. While, in contrast, the Milojevic et al, ${ }^{11}$ study found stronger associations of all MI and NSTEMI with $\mathrm{NO}_{2}$ at lags 0-4 days rather than $\mathrm{NO}_{2}$ at lags $0-1$ days, our sensitivity analyses with modelled pollutant data (figure 1) suggested stronger associations with the more recent exposure (ie, lag 0 days) than lags 1 or 2 days.

\section{Mechanisms}

Much has been written and hypothesised as to the various possible mechanisms by which an increase in the level of exposure to certain pollutants may increase the risk of an acute coronary event, including by increasing blood pressure, blood viscosity, promoting an inflammatory response, interfering with heart rhythm or promoting vasoconstriction. ${ }^{3}{ }^{4}$ Of interest here is how these mechanisms may differentially impact on STEMI and NSTEMI. The total occlusion of a coronary artery characteristic of STEMI is more likely to result from plaque rupture and thrombus formation than the partial occlusion characteristic of NSTEMI. ${ }^{12}{ }^{29}$ Gardner $e t a l,{ }^{12}$ therefore, suggested that whether exposure to a given pollutant (in their case $\mathrm{PM}_{2.5}$ ) was more important in the aetiology of STEMI than NSTEMI may depend on whether or how that pollutant influences the processes leading to thrombus formation and/or thrombus dissolution.

\section{CONCLUSION}

In common with a previous study of the MINAP database ${ }^{11}$ but using a different data set with notably wider geographical coverage, modelled temperature and pollution data modelled by an atmospheric chemistry transport model, we found some evidence of a positive association between exposure to $\mathrm{NO}_{2}$ and the risk of NSTEMI. The appropriate exposure period or lag to consider is still unclear and more immediate effects of other pollutants in the hours rather than the day of and or days prior to event may have been missed. Given our study detected only one positive association, it is possible that this finding is simply an artefact. Confirmation of any such association in databases other than MINAP is therefore required.

Acknowledgements This study includes data collected on behalf of the British Cardiovascular Society under the auspices of the National Institute for Cardiovascular Outcomes Research (NICOR). The use of monitoring data from the UK Department for Environment, Food and Rural Affairs Automated Urban and Rural Network (AURN) for air pollutant monitoring (@ Crown 2015 copyright Defra via uk-air.defra.gov.uk, licenced under the Open Government Licence (OGL)) is acknowledged. The use of emissions data from the National Atmospheric Emissions Inventory (@ Crown 2015 copyright Defra and DECC via naei.defra.gov.uk, licenced under the Open Government Licence (OGL)) is acknowledged. Also licenced under the OGL, the authors acknowledge the use of data on RCGP influenza-like illness (ILI) consultation rates per 100000 population, England and Wales (Source: the Office for National Statistics and the Royal College of General Practitioners Research and Surveillance Centre).

Contributors $B K B$ conducted the main statistical analysis and took the lead in drafting the paper. RWA, MRH, RMD, BGA and PW contributed to the design and concept of the study. AM pre-analysed the MINAP data and constructed the linked database. $\mathrm{CL}$ and MRH assembled the monitor-model comparison data sets and along with BGA and BKB were involved in producing the model performance statistics. IAM, MV and RMD generated the ACTM data and processed it for use in this study. MV is the main developer of the regional EMEP4UK atmospheric chemistry-transport model based on the widely used 
EMEP European regional model. All authors contributed to the drafting of the paper and the interpretation of results.

Funding This work was performed under the cross UK-research councils Environmental Exposure and Human Health Initiative (EEHI) grants: NE/ 1007865/1, NE/I007938/1 and NE/I008063/1. Other than to review the study design as part of the grant giving process, the funders did not have any involvement in the collection, analysis and interpretation of data, in the writing of the report or in the decision to submit the article for publication. The EMEP4UK ACTM is also supported by the UK Department for the Environment, Food and Rural Affairs (Defra) and, the NERC Centre for Ecology and Hydrology (CEH).

Competing interests BKB owns shares in Royal Dutch Shell and Scottish and Southern Energy and her spouse has a deferred Shell pension. Her work on this project was funded by a grant from the UK-research councils Environmental Exposure and Human Health Initiative (EEHI). RWA and RMD report grants from the UK-research councils EEHI, during the conduct of the study. MRH, IAM, CL and PW report grants from the Natural Environment Research Council, during the conduct of the study.

Ethics approval Ethics approval was obtained from the National Research Ethics Service (15/SC/0494).

Provenance and peer review Not commissioned; externally peer reviewed.

Data sharing statement No additional data are available.

Open Access This is an Open Access article distributed in accordance with the terms of the Creative Commons Attribution (CC BY 4.0) license, which permits others to distribute, remix, adapt and build upon this work, for commercial use, provided the original work is properly cited. See: http:// creativecommons.org/licenses/by/4.0/

\section{REFERENCES}

1. World Health Organisation. Review of evidence on health aspects of air pollution-REVIHAAP project: Technical report. WHO Regional Office for Europe 2013. http://euro.who.int/en/health-topics (accessed 9 Mar 2015).

2. Committee on the Medical Effects of Air Pollutants (COMEAP). Cardiovascular disease and air pollution. London: Department of Health, 2006. http://www.comeap.org.uk/documents (accessed 9 Mar 2015).

3. Brook RD, Rajagopalan S, Pope CA III, et al Particulate matter air pollution and cardiovascular disease: an update to the scientific statement from the American Heart Association. Circulation 2010;121:2331-78.

4. Bhaskaran K, Wilkinson P, Smeeth L. Cardiovascular consequences of air pollution: what are the mechanisms? Heart 2011;97:519-20.

5. Nuvolone D, Balzi D, Pepe P, et al. Ozone short-term exposure and acute coronary events: a multicities study in Tuscany (Italy). Environ Res 2013;126:17-23.

6. Goggins WB, Chan EYY, Yang C-Y. Weather, pollution, and acute myocardial infarction in Hong Kong and Taiwan. Int $J$ Cardiol 2013;168:243-9.

7. Cadum E, Berti G, Biggeri A, et al. [The results of EpiAir and the national and international literature]. Epidemiol Prev 2009;33(Suppl 1):113-19, 123-43.

8. Maitre A, Bonneterre V, Huillard L, et al. Impact of urban atmospheric pollution on coronary disease. Eur Heart $J$ 2006;27:2275-84.

9. Bhaskaran K, Hajat S, Hains A, et al. Effects of air pollution on the incidence of myocardial infarction. Heart 2009;95:1746-59.

10. Mustafić $\mathrm{H}$, Jabre $\mathrm{P}$, Caussin $\mathrm{C}$, et al. Main air pollutants and myocardial infarction: a systematic review and meta-analysis. JAMA 2012;307:713-21.

11. Milojevic A, Wilkinson P, Armstrong B, et al. Short-term effects of air pollution on a range of cardiovascular events in England and Wales: case-crossover analysis of the MINAP database, hospital admissions and mortality. Heart 2014;100:1093-8.

12. Gardner B, Ling F, Hopke PK, et al. Ambient fine particulate air pollution triggers ST-elevation myocardial infarction, but not non-ST elevation myocardial infarction: a case-crossover study. Part Fibre Toxicol 2014;11:1.

13. Wang X, Kindzierski W, Kaul P. Air pollution and acute myocardial infarction hospital admission in Alberta, Canada: a three-step procedure case-crossover study. PLoS ONE 2015;10:e0132769.

14. Herrett E, Smeeth L, Walker L, et al. The Myocardial Ischaemia National Audit Project (MINAP). Heart 2010;96:1264-7.

15. Vieno M, Dore AJ, Stevenson DS, et al. Modelling surface ozone during the 2003 heat-wave in the UK. Atmos Chem Phys 2010;10:7963-78.

16. Vieno $\mathrm{M}$, Heal MR, Hallsworth $\mathrm{S}$, et al. The role of long-range transport and domestic emissions in determining atmospheric secondary inorganic particle concentrations across the UK. Atmos Chem Phys 2014;14:8435-47.

17. Simpson D, Benedictow A, Berge $\mathrm{H}$, et al. The EMEP MSC-W chemical transport model-technical description. Atmos Chem Phys 2012;12:7825-65.

18. NICOR. Datasets and user guides. https://www.ucl.ac.uk/nicor/ audits/minap/datasets (accessed 16 May 2016).

19. Weather Research and Forecasting (WRF) model version 3.1.1. http://www.wrf-model.org (accessed 26 Jan 2016).

20. UK National Atmospheric Emissions Inventory (NAEI). (C) Crown 2015 copyright Defra \& DECC via naei.defra.gov.uk, licenced under the Open Government Licence (OGL) http://www.nationalarchives. gov.uk/doc/open-government-licence/version/2/ (accessed 24 Aug 2015)

21. Centre for Emissions Inventories and Projections (CEIP). http://www ceip.at (accessed 26 Jan 2016).

22. Automatic Urban and Rural Monitoring Network (AURN) Data Archive. (C) Crown 2015 copyright Defra via uk-air.defra.gov.uk, licenced under the Open Government Licence (OGL) http://www. nationalarchives.gov.uk/doc/open-government-licence/version/2/ (accessed 9 Jun 2015).

23. Carslaw D. Defra regional and transboundary model evaluation analysis-phase 1, a report for Defra and the Devolved Administrations 2011. http://uk-air.defra.gov.uk/reports/cat20/ 1105091514_RegionalFinal.pdf (accessed 3 Feb 2015).

24. Butland BK, Armstrong B, Atkinson RW, et al. Measurement error in time-series analysis: a simulation study comparing modelled and monitored data. BMC Med Res Methodol 2013;13:136.

25. Bhaskaran K, Hajat S, Hains A, et al. Short term effects of temperature on risk of myocardial infarction in England and Wales: time series regression analysis of the Myocardial Ischaemia Nationa Audit Project (MINAP) registry. BMJ 2010;341:c3823.

26. Janes $H$, Sheppard L, Lumley $T$. Case-crossover analyses of air pollution exposure data: referent selection strategies and their implications for bias. Epidemiology 2005;16:717-26.

27. Office for National Statistics and the Royal College of General Practitioners Research and Surveillance Centre. Weekly deaths from all causes and RCGP influenza-like illness (ILI) consultation rates per 100,000 population, England and Wales, 1999-2013: in Excess Winter Mortality in England and Wales, 2012/13 (Provisional) and 2011/12 (Final). http://www.ons.gov.uk/ons/rel/subnational-health2/ excess-winter-mortality-in-england-and-wales/ 2012-13--provisional--and-2011-12--final-/index.html (accessed 29 Oct 2014) Licenced under the Open Government Licence v3.0 http:// www.nationalarchives.gov.uk/doc/open-government-licence

28. Bhaskaran K, Hajat S, Armstrong B, et al. The effects of hourly differences in air pollution on the risk of myocardial infarction: case crossover analysis of the MINAP database. BMJ 2011;343: d5531.

29. Hong $\mathrm{YJ}$, Jeong $\mathrm{MH}$, Choi $\mathrm{YH}$, et al. Differences in intravascular ultrasound findings in culprit lesions in infarct-related arteries between ST segment elevation myocardial infarction and non-ST segment elevation myocardial infarction. J Cardiol 2010;56:15-22. 